\title{
Study of Improving the Community Governance Mode by Constructing the Demand Ways for the Rational Public Opinion
}

\author{
Yang Yang \\ Southwest University, Chongqing, China \\ Email: yangyangtangxin@vip.qq.com
}

Received 25 August 2015; accepted 13 November 2015; published 17 November 2015

Copyright (C) 2015 by author and Scientific Research Publishing Inc. This work is licensed under the Creative Commons Attribution International License (CC BY). http://creativecommons.org/licenses/by/4.0/

(c) (i) Open Access

\section{Abstract}

The people's good life is from the perfect community governance way. After the Fourth Plenary Session of the 18th CPC Central Committee, the concept of China under the rule of law and a government of law has become its consensus between government and society. In real life, it is becoming a contradiction between a government of law and the community governance that was participated in by inhabitants. Many livelihood issues usually adopted the way of political participation to deal with by inhabitant, rather than adopted the legal way. In essence, a government of law and the community governance that was participated in by inhabitants go together. Through questionnaire survey it is found that it has been caused by the reason that each subject to participate in the community governance was not in the character of a government of law. For example, it is not enough to govern according to the rule of law by the government, the civil servants, the self-governing local organizations and its relevant personnel, and it is low for the inhabitant's legal standard and their participation. This paper finds by analysis that the contradiction is finally dissolved and eliminated by increasing the government financial input and security, actively allotting the high-quality legal personnel for the community and improving the inhabitant's desire and standard to participate in the community life within a government of law framework. And the governance way with the community is improved by constructing the rational ways for the public opinion. Some suggestions are put forward in this paper from the perspective of government and it hopes to promote the community governance model that can be suitable for our country's situation.

\section{Keywords}

The Community Governance, A Government of Law, To Participate in the Community Governance 


\section{Introduction}

Since the beginning of the late 90's, the community's construction has been making waves in the large- and medium-sized cities of China. The Ministry of Civil Affairs of the People's Republic of China firstly chose Beijing, Shanghai, Tianjin, Shenyang, Wuhan, Qingdao and other places to establish 26 national communities' building experimentation area. The several representatives of urban communities' governance model were formed through its practices and experiences for several years, such as the Shanghai model, Shenyang model, Jianghan model and so on (He, 2015). It is a historical process in China for the rise and development of the urban community governance, its forward steps continue to meet the new requirements of social development as a microcosm of society. At present, with the quick development of our urbanization and the continuous improvement of market economy, the community is also gradually changing from the unit system community to the socialization community. As the diversified organization of the community personnel and the uneven quality of personnel, it makes the various matters of its management and services continued to increase, at the same time, it makes the existing way of the community governance and the relevant laws discordant, such as, Organic Law of Urban Residents Committee of the People's Republic of China and so on. So it is very obvious that the relevant law has not met the community management's requirement. The concept of China under the rule of law and a government of law has become their consensus between government and society after the Fourth Plenary Session of the $18^{\text {th }}$ CPC Central Committee. The residents' need for the community not only has emphasized the economic dependence, but also is more and more eager for the more effective legal services to ensure their quality of life. In order to thoroughly carry out the new governance of law's concept by president Xi Jinping, which he emphasized the current social governance should scientifically legislate, strictly enforce the law, ensure an impartial judicature, abide the law by all the people, supervise and restrict it, it should be fit perfectly into the community governance to carry out the law construction's scheme, at the same time, to improve the civil rule of law' quality in China. A seat would be won in the rule-based society when it will be an essential skill for all people in China to apply the law. By analyzing the bad part that each subject is playing role in the current community governance mode when the rule of law's thought is intervened, the deviation that the rule of law's community is constructed should be found out and timely be corrected to put forward the perfect and operable suggestions through combining with the real life.

\section{The Conflict of the Community Governance and Public Opinion's Demand}

Through analyzing that all subject of the community governance themselves is an obstacles to construct the demand for the rational public opinion, it can be comprehensively understood why the rule of law and to participate in the community by residents become a pair of contradictions.

\subsection{The Shortage of Financial Support for the Community Law Service's Construction}

It contains more than a dozen terms for the community service in today, such as, the social assistance, the federation of the disabled, the basic medical insurance for urban residents, the handling department for the residents complaints, the women federations, the party members management etc. At present, the government has formed a set of the complete people's livelihood service system. Many services in the community service tend to the people's livelihood as the social security service, the social relief service, the health care service and other services. So the government departments have made many funds invest in the health care, the social security and so on that is related to the public service of people's livelihood in the financial support for the community service in recent years, it also makes the services be ignored, which can raise its autonomous ability about the residents to handle the complaints and so on. The funds shortage for the legal affair's construction makes the activities of law popularization confine to the ordinary traditional campaign, for example, the small campaign in the community blackboard and so on. But, it can not already meet the residents' requirement for their demands for this traditional publicity of law popularization at present. The activities of law popularization should be given the meaning of time, and not be remained stagnant. So, it should also be gradually transformed from telling the 
people what is law to telling the people how to apply the law at present, and it is necessary for this change that the government departments increase their financial support for the community legal affair's construction.

\subsection{The Lack of Actual Effect in the Spirit of Legal Governance}

It will be analyzed from two aspects. The first is to analyze it from the grassroots government civil servants. The Department of Justice for the Opinions to Strengthen the Community Legal Service in Large and Medium-Sized City is issued in 2002, which pointed out that the community legal service in the large and medium-sized city should be strengthened and all people's legal literacy should be improved through the legal service to the community's development. The main goal of the community’s legal services is also suggested in it, which pointed out that the community legal service would be integrated into the program of local economy and social law and the community legal service system should be established in the municipalities directly under the central government, the deputy provincial city and the capital city of the provincial city in three to five years according with the time background in the market economy system (Duan, 2002). It is beautiful without doubt to construct the ideal community governance in the Opinions, but it is not so optimistic as reflected in the practice. Taking the Jingyue economic development zone's Wu community in Changchun Jingyue of Jilin province as example, it is understood through visits that the information office of law at the community often outlived its usefulness, it did not has the affiliated notary, lawyer or law servants with specialized knowledge, and it also did not carry out its law service in a planned and systematic way. So it is all talk to establish a scientific organization structure and a perfect system to popularize law. All are the strong barrier to limit the modern community towards rule by law and build the government of law in community, such as, the management system in community is not perfect, it is not timely for the Opinion's implementation and the staffing is not professional.

The second is the poor popularization of law by the resident's committee. In the $2^{\text {nd }}$ article of the Organic Law of the Urban Residents Committee of the People's Republic of China, it is stipulated that the residents committee is the gross-roots voluntary association of the resident's self-government, self-education and selfservice. That is, the community residents committee is a voluntary association by masses and do not have any administrative characteristic. So the community cadres should be from the community residents who enthuse about the public service. But the real community cadre in practice do most of the work with administrative characteristic, such as the family planning, the management of floating population, the labor and social security etc..This not only makes the community become an administrative media that government manage the residents from top to bottom and damage the independence of voluntary association, but also makes the community cadre often ignore their work, and ignore their duties and responsibilities. Most of community work should provide its service for the residents from the material and spiritual level, rather than spend more time and energy to undertake the government's arduous work. Now, it seems that their work is getting the cart before the house. This work way and tendency is not well geared to the concept that build a country governed according to law today. Because the work of government of law' establishment should be naturally ignored when the community's work is focused on the people's livelihood service. Together with the community staff's law quality is not good and it has no special law servant in the community cadre, the works of law service like the law popularization's activities are often made a perfunctory effort and done carelessly. So that the law service's interaction in community is ended by reasons of the poor organization and so on.

\subsection{The Low Standard of Resident's Law Quality and Low Participation in a Government of Law}

In the market economy, the individual benefits that are extended from the economic interests have been extremely enlarged and the individualism in the interpersonal relation is come, it also makes the conflict between individuals increase. And a large number of complex disputes make people find that has been unable to meet their interests' demand only depending on sophistication, people began to find a more objective and just methods to resolve their disputes and protect their legal rights, this is a simple process that the law consciousness of contemporary people are gradually formed. The resident who lived in community as a small society also have to face the complex interests dispute. Although the rudimentary knowledge of government of law have already been understood, it is not enough that only remain in the rudimentary knowledge of government of law and it is necessary for people that continue to learn the law knowledge and gradually deepen their awareness of a government of law to realize the society governed by law. Actually, it is not enough for the propaganda of govern- 
ment of law in the community law popularization's activities, it is not new and original for its communication means and it is uneven for its effect of the community's law service. Speaking from the objective aspect, it is not standardized for the subject, content, methods and so on of community law service and it is lack of the rational and correct guidance to them. Speaking from the subjective aspect, it can not meet the resident's demand that eager to get the law service as their half knowledge of law, in this way the government of law's awareness that are only just beginning was gradually nipped in the bud.

\section{To Establish a Government of Law's Community}

\subsection{To Increase the Financial Support for the Community Law Service's Construction by Government}

The government should establish a special fund to support the community's law governance in the annual report on the implementation of the central and local budgets. The allotment notification should be given to all county government through the government documents, which is regulated that all county government pay attention to the law service's construction of community in policy and government convey the opinion to establish the convenient lawsuit service platform in system. The government's management function should be played and all efforts should be mobilized to create a convenient and efficient lawsuit service platform. If the leading group of law service is early set up on all county government and all Legal Justice Bureaus, the government should head up all law service works and the Legal Justice Bureau should be responsible for the technical works of allocation and organization, etc... The law service department is established in the sub-district office, which can undertake the superior government's directive and convey the opinion to all districts about law service. Of course, it is only the guidance relationship and is not the political leadership relationship between the sub-district office and all districts. Full self-rule about law service should be given to the community by the sub-district office, in this way, it not only can avoid the needless work procedures and improve their efficiency, but also can make the community create the different service schemes according to the actual situation to improve their service flexibility (Rao, 2013). The workstation of law service is firstly established at community, and then, the different lawsuit platform are created in the workstation. And the internal personnel in the workstation are uniformly allocated from different law firm, procurator-ate and public authorities by Legal Justice Bureau. So that it not only ensure the division of labor' scientificity, and ensure the legal personnel specialization.

\subsection{The Staff Allocation on the Community Legal Platform}

The community should make full use of the allocated funding by the district (county) government. To improve their organization's law service system of community, the platform that is special to solve the dispute and the platform that is special to provide the legal consultation should be established on the workstation. This labor division can make the organization institutionalization and standardization. And the most importance to establish the law platform is that the staff have some law literacy and experiences can be learned from some developed provinces in the staff allocation. For example, the legal service agreement was contracted among Jingde Law Firm of Beijing, Chang An Notary Office of Beijing and District Seven's community cadres of He Pingli Avenue in Beijing and they formed a permanent system of long-term cooperation, which not only makes their officers within the community improve their profession, but also provides the working experience for new officer who is just entering to work in the field of law. That is, the law firms and the notary offices can let their trainees work and experience in the community, which is the best experience and training places because the residents in the community is from different social strata and the legal disputes is complex ( $\mathrm{Lv} \& \mathrm{Li}, 2013)$.

\subsection{To Train Their Desire and Standard for a Government of Law}

Today, only depending on a department's right under construction of legal service, it often can not meet the different interest demands and the individual pursuit for a spirit, because there has been a social base of corporate governance. It can not only play a good role in long time and can certainly play a bad role to stifle their initiative if the top-down management mode is only adopted. So that, it will perfectly combine the guidance and self-learning to play a good legal service's role in the society of corporate governance within law, which can be formed only combining the top-down autonomous mode. On the one hand, for the community staffs, they should be regularly organized to learn the law curriculum, train their spirit of law and their legal practice ability, solve 
the residents' dispute by means of the law. A series of rules and regulations are adopted, such as, the incentive assessment system, the assessment appraisal system and so on. At the same time, the evaluation results is regarded as an important basis for the work performance or their annual registration, which are uniformly managed by the district or county government (Ye, 2014). On the other hand, for the residents, the incentive methods can be adopted, for example, the prizes are established in the regular law quiz. The residents should be encouraged to participate in the activities which can entertain or learn and improve their legal literacy to participate in a government of law.

\section{Conclusion}

It is the two aspects of one problem for a government of law and the residents' participation, which unified the practice to construct the socialist rule of law society. With the development of a rule of law in Chinese today, it is the essential quality for the modern people to learn to resolve the interest disputes in their life by means of the law. The community's governance is as the epitome to construct the social governance, and the government can not ignore to construct the community's legal service in a moment of weakness. Nowadays, there are many problems to establish the legal service in the community's government of law. So the program to innovate the community's governance ways and to establish the rule of law community should be on the agenda as soon as possible. The experiences should be accumulated in practice and the traditional thinking mode should be changed. The management and service, the service and rule of law, the government's management mode from top to bottom and the community's autonomy mode from bottom to top should be combined, it can provide protection for the public opinion's demand to eventually dissolve and eliminated the conflicts only in this way. The community's governance mode will be improved by constructing the demand ways for the rational public opinion.

\section{References}

Duan, Z. K. (2002). The Speech about Comprehensively Promoting the Health Development of the Community’s Legal Service in the Work Forum of the Community's Legal Service in Medium-Size Cities in the Country(Abstract). China Notary, 5, 4-5.

He, H. B. (2015). Study on the Comparison and Analysis of the Urban Community Governance Model in China. Zhuhai Tide, 1, 55-56.

Lv, T., \& Li, X. X. (2013). Research on the Community’s Legal Service Mechanism—Based on the Community’s Legal Service Survey in Yunnan Province of China. The journal of Yunnan Administration College, 2, 125-129.

Rao, C. L. (2013). Study of the Administrative System's Change and the System's Improvement of the Sub-District Office in China. Chinese Public Administration, 2, 85-88.

Ye, W. (2014). Study on the Urban Community Governance Model in the Process of Urbanization (pp. 46-48). Changsha: Hunan Normal University. 